\title{
SISTEM INFORMASI DATA PENDUDUK BERBASIS ANDROID DAN WEB MONITORING STUDI KASUS PEMERINTAH KOTA KARAWANG (Penelitian dilakukan di Kab. Karawang)
}

\section{Baenil Huda}

\author{
Sistem Informasi, Fakultas Teknologi dan Ilmu Komputer, UBP Karawang \\ Jl. HS.Ronggo Waluyo, RT.014/RW.009, Puseurjaya, Telukjambe Timur, \\ Kabupaten Karawang, Jawa Barat 41361 \\ baenil88@ubpkarawang.ac.id
}

\begin{abstract}
ABSTRAK
Tujuan penelitian adalah untuk (a) Mengetahui status dan jumlah penduduk secara real time. (b) Membuat rekam jejak tempat tinggal penduduk. Dalam penelitian ini, metode yang digunakan adalah metode pengambilan sample, dengan dilengkapi perangkat Android yang akan digunakan dalam penginputan data penduduk dan Web Monitoring sebagai penyedia informasi data penduduk. Dari hasil penelitian ini diharapkan mendapat data penduduk yang valid sesuai dengan kondisi sebenarnya. Serta tidak adanya penyalah gunaan dan manifulasi data penduduk. Khususnya bagi masyarakat daerah perumahan yang berada di Desa Sukasari Kecamatan Purwasari Kabupaten Karawang.
\end{abstract}

Kata Kunci : Real time, rekam jejak, perangkat Android, Web Monitoring.

\section{Pendahuluan}

\subsection{Latar Belakang}

Dalam masalah kependudukan sudah merupakan masalah serius yang bukan saja dihadapi oleh Negara - Negara yang sedang berkembang, tetapi juga oleh Negara - Negara maju karena banyak menyangkut segi kehidupan. Perencanaan pembangunan yang sejalan dengan kebijaksanaan yang dituangkan dalam upaya meningkatkan kesejahteraan rakyat baik di daerah perkotaan maupun di daerah pedesaan dimana aspek kependudukan perlu dipertimbangkan sebagai tolak ukur pembangunan masyarakat.

Penduduk merupakan objek yang sekaligus sebagai subjek dalam pembangunan nasional. Kebijaksanaan dibidang kependudukan bukan saja hanya menyangkut jumlah dan kepadatan penduduk, arus imigrasi, kelahiran serta kematian tetapi juga kebijakan dalam mengendalikan pertumbuhan penduduk yang tinggi serta mengarahkan mobilitas dan sebaran penduduk yang lebih merata, terutama didaerah yang jarang penduduknya, dengan memperhatikan daya dukung alam serta lingkungan, dinamika penduduk tanpa disertai dengan kontrol untuk mengatur jumlah penduduk yang diinginkan akan disertai dengan kontrol untuk mengatur jumlah penduduk yang diinginkan akan menimbulkan permasalahan sosial dan ekonomi dengan segala akibatnya. Pertambahan penduduk yang sangat besar akan mempengaruhi sarana dan prasarana dibidang pendidikan, kesehatan, pemukiman, kesempatan kerja dan hal sebagainya.

Usaha-usaha yang dilakukan pemerintah dan masyarakat dewasa ini sangat mempengaruhi demografi dimasa mendatang, masalah kependudukan erat kaitannya dengan manusia sebagai anggota masyarakat maupun perorangan, karena itu pengetahuan tentang kependudukan harus diketahui oleh seluruh lapisan masyarakat dan tidak terbatas hanya untuk para ilmuwan saja.

Oleh karena persoalan tersebut diatas yang didasari latar belakang yang juga sudah dijelaskan, Penelitian ini akan mencoba membangun sebuah aplikasi mobile yang 
menyediakan berbagai informasi real time menggunakan perangkat Android untuk mempermudah dalam menginput data dan mengakses informasi yang sudah di sediakan oleh suatu web sebagai monitoring yang menyediakan informasi tersebut.

\subsection{Perumusan Masalah}

a. Bagaimana pemerintah mendapatkan data warga pendatang dan warga asli karawang?

b. Bagaimana pemerintah memiliki data penduduk yang berstatus tempat tinggal sewa/ ngontrak yang berada di perumahan dan di perkampungan secara cepat dan akurat?

c. Bagaimana pemerintah bisa memberikan pelayanan yang cepat terhadap warga-nya?

d. Bagaimana pemerintah bisa memberikan pelayanan yang cepat terhadap warga pendatang yang membutuhkan ijin tinggal?

\section{Tinjauan Pustaka}

\subsection{Pengertian Sistem Informasi}

Sistem adalah suatu kumpulan objek-objek yang saling berhubungan dan berinteraksi satu sama lain serta menjadi satu kesatuan untuk mencapai suatu tujuan. Karakteristik sistem terdiri dari komponen sistem, batasan sistem, lingkungan luar sistem, penghubung sistem, masukan sistem, keluaran sistem, pengolahan sistem, dan sasaran sistem.

Informasi adalah suatu hasil dari pengolahan data yang memiliki nilai tertentu dan bisa memberikan kegunaan bagi para penerimanya. Informasi dapat didefinisikan sebagai hasil dari pengolahan data dalam suatu bentuk yang lebih berguna dan lebiih berarti bagi penerimanya yang menggambarkan suatu kejadian-kejadian (event) yang nyata (Fact) yang digunakan untuk pengambilan keputusan (Jogiyant: 1999).

\subsection{Pengertian Penduduk}

Dalam keputusan Mentri Dalam Negeri NO 54 tentang kependudukan pedoman penyelenggaraan pendaftaran penduduk yang dijelaskan diantaranya:

Penduduk adalah Warga Negara Indonesia (WNI) dan Warga Negara Asing (WNA) pemegang ijin tinggal tetap di wilayah Negara kesatuan republic Indonesia atau semua orang yang berdomisili di Desa tersebut selama enam bulan lebih atau mereka yang berdomisili kurang dari enam bulan tetapi bertujuan menetap.

\subsection{Pengertian Android}

Android adalah sistem operasi berbasis Linux yang dimodifikasi untuk perangkat bergerak (mobile device) yang terdiri dari sistem operasi, middleware, dan aplikasi-aplikasi utama. Awalnya, Andorid dikembangkan oleh Android inc. perusahaan ini kemudian dibeli oleh Google pada tahun 2005. Sistem operasi Android kemudian diluncurkan bersamaan dengan dibentuknya organisasi Operasi Handset Alliance tahun 2007. Selain Google, beberapa nama-nama besar juga ikut serta dalam Open Handset Alliance, Antara

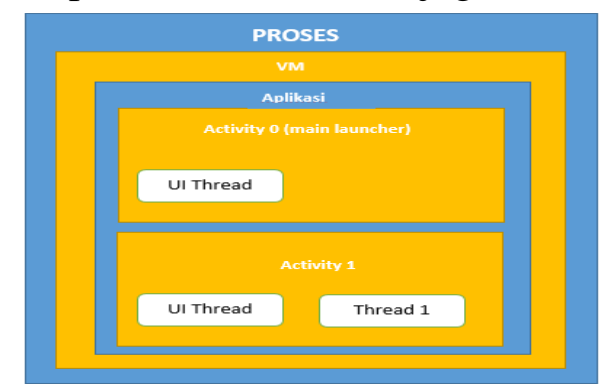




\section{Gambar : Model Aplikasi Android}

\subsection{Pengertian Web}

Website adalah kumpulan halaman web yang saling terhubung dan file-filenya saling terkait. Web terdiri dari page atau halaman, dan kumpulan halaman yang dinamakan homepage. Homepage berada pada posisi teratas, dengan halaman-halaman terkait berada di bawahnya. Biasanya setiap halaman di bawah homepage disebut child page, yang berisi hyperlink ke halaman lain dalam web (Gregorius, 2000:30).

\section{Tujuan dan Manfaat Penelitian}

\subsection{Tujuan Penelitian}

- Agar dapat mengetahui status dan jumlah penduduk secara real time, untuk itu harus dibuat suatu sistem informasi di pemerintahan desa yang terintegrasi langsung ke warga masyarakat. Sehingga dapat mendukung proses tersebut.

- Penelitian ini juga bertujuan, agar dapat membuat rekam jejak tempat tinggal penduduk. Maka diperlukan suatu sistem yang terintegrasi ke database sistem pemerintahan sebagai media penyimpanan data penduduk.

\subsection{Manfaat Penelitian}

Dalam penelitian ini diharapkan berguna untuk:

- Pemerintahan, mengetahui perubahan jumlah penduduk dengan cepat dan akurat. Sehingga dapat mengambil tindakan yang akan dilaksanakan untuk tahun-tahun berikutnya dalam mengatasi pertambahan penduduk yang ada. Khususnya pertambahan penduduk di Desa Sukasari Kecamatan Purwasari Kabupaten Karawang.

- Hasil penelitian ini dapat di jadikan informasi bagi Pemerintahan Desa dan warga masyarakat dalam hal data kependudukan.

- Sebagai bahan evaluasi khususnya bagi Pemerintahan Desa Sukasari dalam proses perijinan tempat tinggal, dan status tinggal warganya.

\section{Metodologi Penelitian}

\subsection{Metode Pengumpulan Data}

Penelitian ini menggunakan pendekatan kualitatif dengan metode yang digunakan yaitu metode studi kasus. Gempur Santoso (2005:30) mengatakan bahwa studi kasus adalah penelitian yang pada umumnya bertujuan untuk mempelajari secara mendalam terhadap suatu individu, kelompok, lembaga, atau masyarakat tertentu. Tentang latar belakang, keadaan sekarang, atau interaksi yang terjadi.

Deskriptif Kualitatif (Nana Sudjana : 203) adalah penelitian yang data-datanya berupa kata-kata (bukan angka-angka, yang berasal dari wawancara, catatan laporan, dokumen dll) atau penelitian yang di dalamnya mengutamakan untuk pendiskripsian secara analisis sesuatu peristiwa atau proses sebagaimana adanya dalam lingkungan yang alami untuk memperoleh makna yang mendalam dari hakekat proses tersebut

Dalam penelitian ini penulis menggunakan tiga macam teknik pengumpulan data, yaitu: Observasi, Wawancara, dan Dokumentasi.

\subsection{Metode Pengembangan Sistem Informasi}

Metode pengembangan sistem yang digunakan untuk membangun sistem ini adalah Model Waterfall. Waterfall adalah suatu metode pengembangan perangkat lunak yang mengusulkan pendekatan kepada perangkat lunak sistematik dan sekuensial yang mulai 
pada tingkat kemajuan system pada seluruh analisis, design, kode, pengujian dan pemeliharaan.

Alasan peneliti menggunakan metode waterfall karena pengaplikasian menggunakan model ini mudah, kelebihan dari model ini juga ketika semua kebutuhan sistem dapat didefinisikan secara utuh, eksplisit dan benar di awal project, maka waterfall dapat berjalan dengan baik dan tanpa masalah. Walaupun tahap demi tahap yang dilalui harus menunggu selesainya tahap sebelumnya dan berjalan berurutan.

Beberapa tahap-tahap metode waterfall, yaitu: seperti gambar di bawah ini.

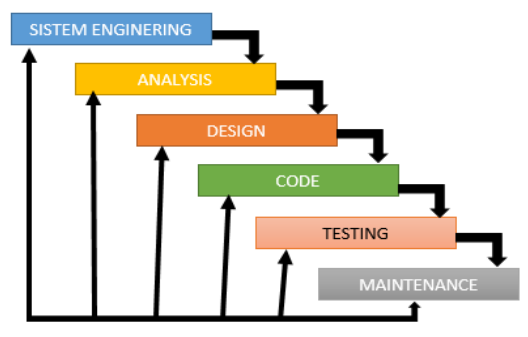

Gambar : Metode

Waterfall

Secara detail penjelasan gambar, yaitu:

1. System Enginering, merupakan bagian awal dari pengerjaan suatu proyek perangkat lunak. Dimulai dengan mempersiapkan segala hal yang diperlukan dalam pelaksanaan proyek.

2. Analysis, merupakan tahapan dimana System Enginering menganalisa segala hal yang ada pada pembuatan proyek atau pengembangan perangkat lunak yang bertujuan untuk memahami sistem yang ada, mengidentifikasi maslah dan mencari solusinya.

3. Design, merupakan tahapan penerjemah dari keperluan atau data yang telah dianalisis ke dalam bentuk yang mudah dimengerti oleh pemakai (user).

4. Coding, merupakan tahapan penerjemah data yang dirancang ke dalam Bahasa pemograman yang telah ditentukan.

5. Testing, merupakan tahapan uji coba terhadap sistem atau program setelah selesai dibuat.

6. Maintenance, merupakan tahapan penerapan sistem secara keseluruhan disertai pemeliharaan jika terjadi perubahan struktur, baik dari segi software maupun hardware.

\section{Hasil dan Luaran}

\subsection{Hasil Wawancara}

Berdasarakan data hasil wawancara diatas dapat disimpulkan bahwa identifikasi masalah yang ditemui di Desa Sukasari Antara lain:

- Dalam hal input dan proses data penduduk yang masih sangat manual yaitu masih dicatat di dalam buku laporan dan disimpan di dalam box file/ lemari file.

- Untuk mendapatkan informasi data penduduk. Warga Desa Sukasari harus datang langsung ke kantor Desa.

- Pada saat pembuatan laporan masih menggunakan sistem manual yaitu merekap data satu per satu, sehingga perlu pembukuan ulang.

- Dalam penyimpanan data penduduk masih menggunakan Microsoft excel dan pembukuan. Hal ini tentunya kurang efektif mengingat banyaknya penduduk yang bertambah maupun penduduk yang pindah, penduduk mati, penduduk pendatang dan penduduk lahir yang berganti setiap bulan

\subsection{Hasil Perancangan Sistem}

65 | B u a n I I m u 
Tabel 4.6. Identifikasi Atributs dan Methods

\begin{tabular}{|c|c|c|c|}
\hline No & Class & Attributes & Methods \\
\hline 1 & \begin{tabular}{|l} 
Penduduk \\
\end{tabular} & \begin{tabular}{|l} 
No Kartu Keluarga, Password, Level \\
\end{tabular} & Login \\
\hline 2 & Kartu Penduduk & $\begin{array}{l}\text { Nama Lengkap, No Kartu Keluarga,NIK, } \\
\text { Jenis Kelamin, Tempat Lahir, Tanggall } \\
\text { Lahir, Alamat, Agama, Pendidikan, } \\
\text { Pekerjaan, Status, Perkawinan, } \\
\text { Kewarganegaraan, No Paspor, No Kitas, } \\
\text { ayah, Ibu. }\end{array}$ & $\begin{array}{l}\text { Tambah } \\
\text { Simpan } \\
\text { Edit } \\
\text { Hapus }\end{array}$ \\
\hline 3 & Kelahiran & $\begin{array}{l}\text { No, No Kartu Keluarga, hari, Tanggal, } \\
\text { Tempat Lahir, Jenis Kelamin, Nama } \\
\text { Lengkap, Nama Ibu, Umur Ibu, Agama } \\
\text { Ibu, Nama Ayah. }\end{array}$ & \begin{tabular}{|l|} 
Tambah \\
Simpan \\
Ubah \\
Hapus \\
\end{tabular} \\
\hline 4 & Kematian & \begin{tabular}{|l|} 
No, No Kartu Keluarga, Nama Lengkap, \\
Jenis Kelamin, Umur, Pekerjaan, Alamat, \\
Hari, Tanggal,Tempat, Penyebab, Pelapor
\end{tabular} & $\begin{array}{l}\text { Tambah } \\
\text { Simpan } \\
\text { Ubah } \\
\text { Hapus }\end{array}$ \\
\hline \multirow[t]{2}{*}{5} & Pindah & $\begin{array}{l}\text { No Kartu Keluarga, Nama Lengkap, } \\
\text { Tempat, tanggal Lahir, Jenis kelamin, }\end{array}$ & $\begin{array}{l}\text { Tambah } \\
\text { Sikmpan }\end{array}$ \\
\hline & & \begin{tabular}{|l|} 
Pekerjaan, Pendidikan Terakhir, Status \\
Perkawinan, Kewarganegaraan, Agama, \\
Alamat Asal, Pindah Ke, Desa \\
Kelurahan, Kecamatan, Kabupaten Kota, \\
Propinsi, Tanggal Pindah, alasan Pindah. \\
\end{tabular} & $\begin{array}{l}\text { Ubah } \\
\text { Hapus }\end{array}$ \\
\hline 6 & Datang & $\begin{array}{l}\text { NO Kartu Keluarga, Nama Lengkap, } \\
\text { Tempat, Tanggal Lahir, Jenis Kelamin, } \\
\text { Pekerjaan, Pendidikan Terakhir, Status } \\
\text { Perkawinan, Kewarganegaraan, Agama, } \\
\text { Alamat Asal, Pindah Ke, Desa } \\
\text { Kelurahan, Kecamatan. }\end{array}$ & $\begin{array}{l}\text { Tambah } \\
\text { Simpan } \\
\text { Ubah } \\
\text { Hapus }\end{array}$ \\
\hline
\end{tabular}
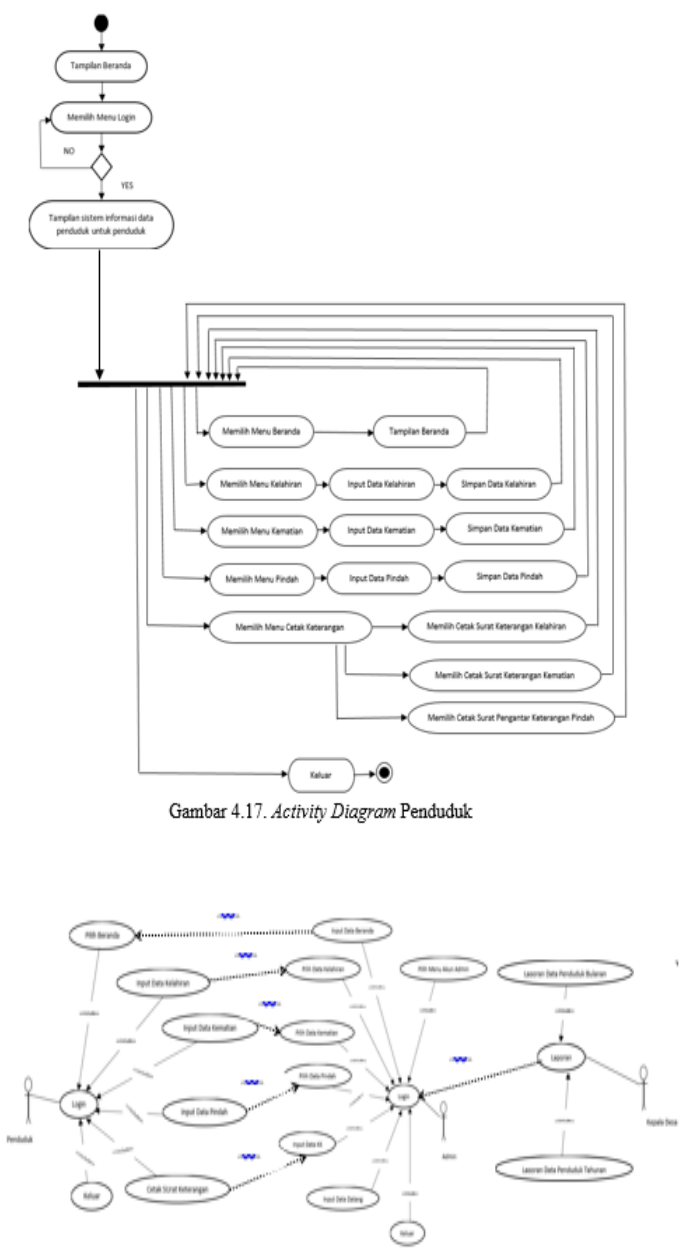

Gambar 4.19. Uge Case Sistem Informasi Kependudukan 


\subsection{Hasil Perancangan Layer Antarmuka}

\subsubsection{User Interface untuk Android}

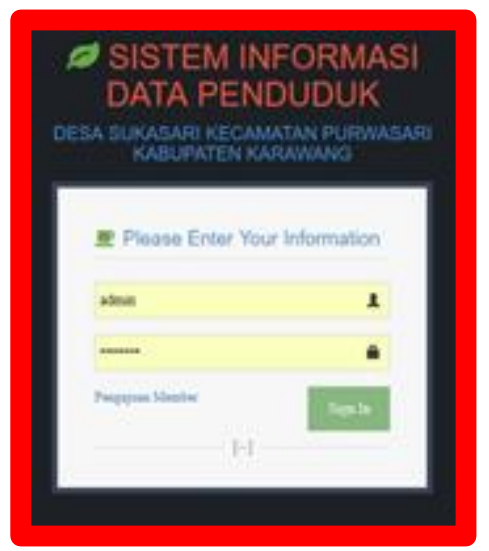

Gambar: Login user dan password

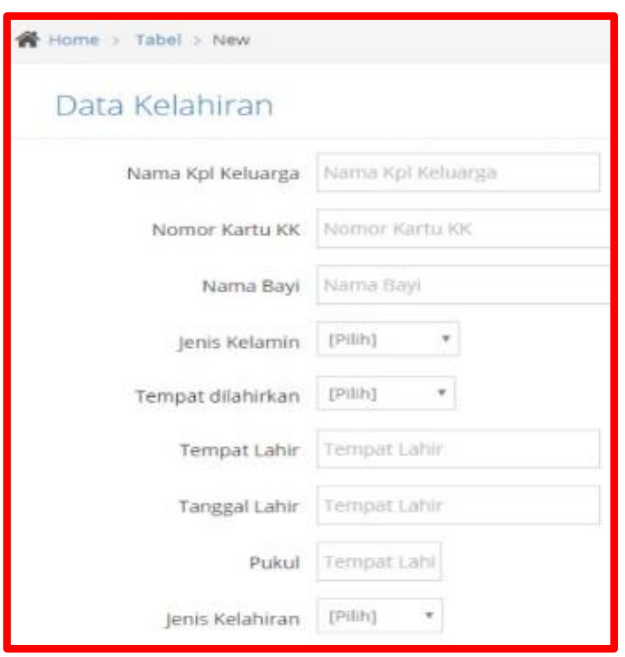

Gambar: Input Data Kelahiran

\subsubsection{User Interface untuk Web}

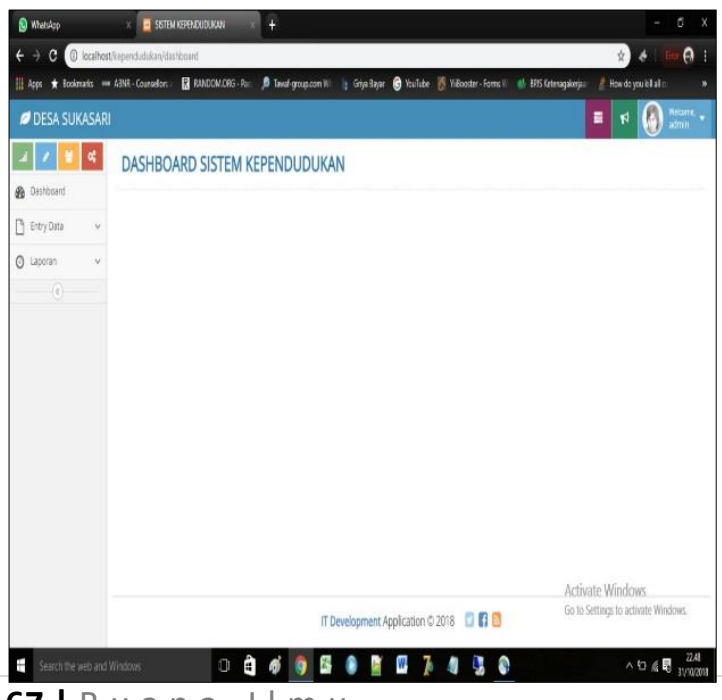

67 | B u a n a I I m u 


\section{Gambar : Dashbor Website}

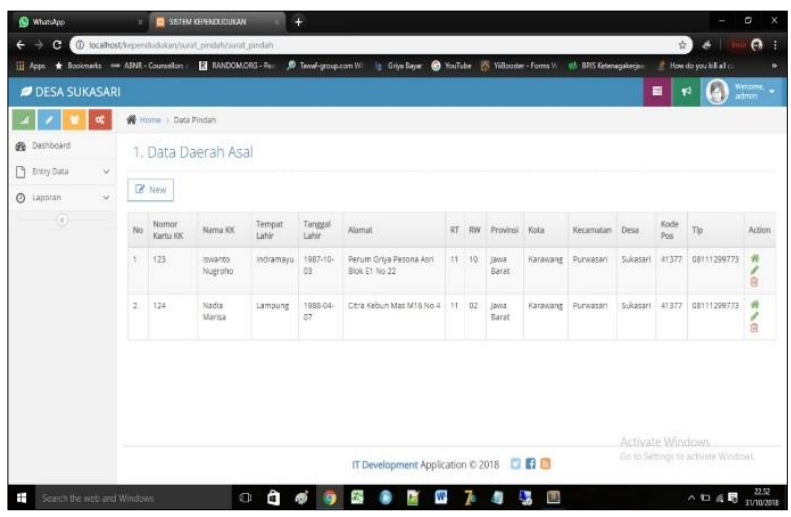

Gambar: Laporan Data Daerah Asal

\subsection{Analisis Kebutuhan Sistem}

\subsubsection{Konfigurasi Hardware}

a. Hardware pendukung Android

1. Komputer Prosesor i3

2. RAM 8 GB

3. Hardisk $500 \mathrm{~GB}$

4. Hp Android Xiomi

b. Hardware pendukung Website

1. Komputer Prosesor i3

2. RAM 8 GB

3. Hardisk $500 \mathrm{~GB}$

\subsubsection{Konfigurasi Software}

a. kebutuhan software Android

1. Windows 10

2. Eclipse IDE

3. Android SDK

4. Emulator Android

b. kebutuhan software Website

1. Windows 10

2. Notepad++/Sublime Text 3

3. Codeigniter 3.1

4. Xampp

5. HeidiSQL

\section{Kesimpulan Dan Saran}

\subsection{Kesimpulan}

Kesimpulan yang diperoleh dari hasil penelitian yang dilakukan menunjukan bahwa dalam proses pendataan penduduk harus menggunakan teknologi perangkat berbasis Android guna kecepatan dan keakuratan data yang diproses. Sehingga dalam pendaftaran dan pengelolaan data kelahiran, kematian dan pindah datang dan pembuatan laporanlaporan mengenai jumlah penduduk sesuai yang diharapkan.

\subsection{Saran}


Penerapan sistem informasi diharapkan dapat digunakan dengan baik sehingga pendataan data penduduk sesuai dengan permintaan warga masyarakat dan tidak adanya penumpukan data di aparat setempat seperti RT ataupun RW.

\section{DAFTAR PUSTAKA}

[1]. Abdul K., From Zero to A Pro - Pemograman Aplikasi Android. CV.Andi Offset. Yogyakarta 2013.

[2]. Ali I., Ahmad R., Lina O., Rancang Bangun Pencatatan Data Kependudukan Kelurahan Pahlawan Berbasis Web. ISSN: 2355-4614 Vol.08/No.01/2016.

[3]. Budi R., Mudah Belajar PHP Teknik Penggunaan Fitur-Fitur Baru dalam PHP 5. Informatika Bandung 2015.

[4].Dr.Eng.Sianipar R.H., PHP \& MySQL Langkag Demi Langkah. CV.Andi Offset. Yogyakarta 2015.

[5]. Dwi P., SIska I., Sistem Informasi Data Penduduk Pada Desa Bogoharjo Kecamatan Ngadirojo Kabupaten Pacitan. ISSN: 2302-5700 Vol.02/No.04/2013.

[6].Eka A., Eko R., Erwin G.,Perancangan Sistem Informasi Kependudukan Berbasis Web. ISSN: 2302-7339 Vol.11/No.02/2014.

[7]. Endang A., Yayat S., Perancangan Sistem Informasi Administrasi Kependudukan Sebagai Pengembangan E-Government. ISSN: 2540-7902 V01.02/No.01/2017.

[8]. One Y., Sukadi, Sistem Informasi Pengolahan Data Kependudukan Desa Purwosari. ISSN: 2088-0154 Vol.07/No.01/2015.

[9]. Zamrony P. J., Panduan Lengkap Pemograman Android. CV.Andi Offset. Yogyakarta 2016.

[10]. Pressman, Roger S. (2001). Software Engineering A Practitioner's Approach Fifth Edition. New York: Mc Graw Hill Higer Education.

[11]. Margono S. Drs. 2007. Metologi Penelitian Pendidikan Komponen MKDK. PT. Rineka Cipta, Jakarta

[12].http://tipsserbaserbi.blogspot.co.id/2016/02/pengertian-website-menurut-para ahli.html (9 desember 2016/14:31:05).

[13].http://www.sarjanaku.com/2011/06/metode-dokumentasi.html (9 desember 2016/16:51:05).

[14].http://expresisastra.blogspot.co.id/2013/11/macam-macam-teknik-pengambilansampel.html (9 desember 2016/17:01:05). 